CADERNOS GESTÃo PÚBLICA E CIDADANIA

\title{
A PRODUÇÃO DA AGENDA SOCIAL: UMA DISCUSSÃO SOBRE CONTEXTOS E CONCEITOS
}

Silvio Caccia Bava 


\section{O Autor}

\section{Sílvio Caccia Bava}

Sociólogo,diretor do Instituto Polis e da Associação Brasileira de ONGs.

* Texto apresentado no Seminário: Mitos e realidades sobre inclusão social, participação cidadã e desenvolvimento local. Córdoba, 21 e 22 de novembro - Argentina 


\section{ÍNDICE}

1. Um Marco de Referência para a Discussão ........................................................................ 5

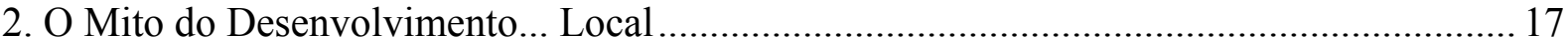

3. A Questão da Participação Popular.......................................................................................... 24

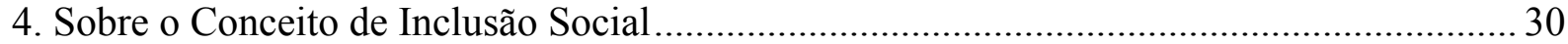




\section{Um Marco de Referência para a Discussão}

Este texto se propõe a explorar um tema amplo e difícil, mas que traz implicações diretas para as ONGs do Sul. Diz respeito a um campo de disputas quanto às identidades, compromissos, alianças, perspectivas, destas ONGs no cenário global atual. Um campo de disputas, é preciso reconhecer desde já, assimétrico, no qual a capacidade de produção de conhecimentos e a capacidade de comunicação são elementos estratégicos.

A pergunta é: como são construídas as agendas sociais nas quais se engajam as ONGs e que implicações isso tem com os limites e potencialidades de nossos trabalhos enquanto agentes de mudança social?

Nesse momento há uma inquietação muito grande da parte de uma parcela das ONGs brasileiras. Nos anos 90 elas viram seu léxico, articulado em torno dos temas da cidadania, apropriado por empresas, governos e organismos multilaterais. Ao mesmo tempo outras questões penetraram seu universo: eficiência e eficácia, indicadores de resultados, planejamento estratégico e gerência por objetivos, temas do mundo da administração das empresas. Também os governos inovaram no discurso e adotaram uma nova postura: buscam ONGs para execução de projetos sociais, apresentam propostas de parcerias com a sociedade civil como recurso para a solução dos problemas sociais.

Neste novo cenário neoliberal dos anos 90 - marcado pela desconstrução de direitos e por políticas assistenciais, focalizadas e compensatórias - criou-se uma linguagem que acaba por se impor ao conjunto da sociedade, gerando um campo de indeterminações, uma zona cinzenta, uma mistura de identidades, na qual a situação atual das ONGs que se identificam enquanto grupos de cidadãos que se organizam para a defesa e ampliação de direitos, para dizer o menos, tornou-se bastante difícil e complexa.

Os novos discursos assumidos por empresas e pelo Estado aproximam estas instituições do léxico das ONGs de tal forma que muitas vezes suas identidades se confundem. Nas palavras de Paulo Arantes: "De uns tempos para cá, autoridades governamentais desandaram a gesticular e arengar como se fossem militantes de uma $\mathrm{ONG}$, de todas as ONGs, misteriosamente eleitos pela mão invisível do destino para advogar a boa causa da sociedade, ocupando, porém, graças sabe-se lá a que manobras astuciosas da razão, postoschave no aparelho do Estado, sobretudo os diretamente concernidos por uma enteléquia cívica denominada "o social". Depois de referir-se às novas atitudes do Estado, o autor observa que: "também as empresas, por uma espécie de esquizofrenia programada, 
principiaram a se comportar em público como se fossem de verdade organizações não lucrativas! No fundo, se ainda distribuem dividendos para seus acionistas, é por mera e incontrolável decorrência técnica de sua maior eficácia no uso de bens escassos. Em primeiro lugar viriam os incontornáveis direitos de cidadania - como seria de esperar dessas verdadeiras centrais de recursos à disposição da sociedade." 1

Mas a inquietação destas ONGs não é só com uma confusão semântica. Ela vai para além do desafio de preservarem suas identidades, seus projetos, sua missão enquanto educadores populares comprometidos com a construção da cidadania e a radicalização da democracia. A inquietação diz respeito, principalmente, à capacidade dos novos discursos gerados pelos governos, empresas e agências multilaterais - e assimilados por grande parte da sociedade civil organizada - confundirem o campo das disputas de interesses e dos conflitos políticos em nossa sociedade, apresentarem propostas impossíveis e mesmo assim se afirmarem como o discurso hegemônico.

Surpreende igualmente a incapacidade destas ONGs elaborarem criticamente esse novo discurso e criarem respostas que reponham a dimensão do conflito na esfera pública e a disputa por recursos públicos e políticas como o caminho para a superação dos problemas sociais.

\section{A disputa de significados e a configuração do campo da política}

As dificuldades destas ONGs não são apenas suas. São de todo um conjunto de atores sociais que se posicionam na contramão de um cenário em que as políticas públicas acentuam os processos de exclusão social e a desigualdade pela via da flexibilização das relações de trabalho, pela redução do salário, pelo aumento do desemprego, pela redução da cobertura e da qualidade das políticas sociais.

O que está em disputa é o diagnóstico das causas da crise social e as propostas para se enfrentar o acirramento desta crise. Para ser mais concreto, por exemplo, o que está em disputa é qual o papel do Estado, qual o desenho das políticas públicas e qual a destinação da receita pública.

A resposta do conjunto de forças políticas que garante a continuidade das políticas neoliberais é de que o enfrentamento da crise social se dá pela via da implementação de políticas de caráter emergencial e destinadas apenas aos grupos mais vulneráveis. E como

\footnotetext{
${ }^{1}$ A esse respeito existe uma importante contribuição ao debate no texto de Paulo Arantes, "Esquerda e direita no espelho das ONGs", publicado pela Associação Brasileira de ONGs - ABONG, nos Cadernos Abong n 27, de maio de 2000, que leva o título de "ONGs identidade e desafios atuais".
} 
seu alcance é muito limitado, os governos convocam a "parceria" das ONGs e das empresas para "se engajarem na luta contra a exclusão social".

Existe uma coerência nesta estratégia, uma vez que a restrição imposta às políticas sociais e aos direitos de cidadania é condição para viabilizar o modelo econômico atual. Neste cenário, a proposta de "mudança social", bandeira das ONGs, fica confinada aos limites de melhorar um pouco o que aí está, mantidas as condições atuais de temperatura e pressão.

E é justamente esse "melhorar um pouco o que aí está" que se tornou o fator limitativo das escolhas quanto aos engajamentos que definem a identidade das ONGs. A desarticulação do espaço público e a supressão da política como espaço de expressão dos conflitos de interesses e de negociação deram margem à criação, no plano simbólico, da proposta de um novo campo de parcerias e alianças que antes não existia. Essa situação impactou a agenda tanto dos governos locais progressistas como das ONGs, que passa hoje por uma redução drástica de seu horizonte utópico. Para aqueles que antes se referenciavam no socialismo e numa ética que, entre outros elementos, defende a justiça social, a equidade, a participação ativa da cidadania na condução e fiscalização das políticas públicas, a situação atual é questionadora desta identidade.

Essa agenda do "melhorar um pouco o que aí está" pode ser ilustrada tanto por políticas nacionais como por políticas de governos locais tais como bolsa-escola, renda mínima, micro-crédito, orçamento participativo, programas de geração de emprego e renda, todos projetos articulados a discursos que têm como objetivos promover a inclusão social, o desenvolvimento local, a participação cidadã.

Um olhar mesmo que superficial sobre a amplitude da cobertura destas políticas, sobre os recursos a elas destinados, sobre os resultados a que chegam, permite dizer que seus propósitos estão longe de ser alcançados. Programas de desenvolvimento local que não desenvolvem, programas de inclusão social que não incluem, programas de participação cidadã que não socializam o poder. E que, no entanto, continuam a ser reafirmados como o caminho para se enfrentar a exclusão social e a pobreza.

O modelo imposto pelas forças políticas dominantes atribui ao Estado, na área social, um papel residual, restrito à implementação de políticas compensatórias, focalizadas nos grupos mais pobres entre os pobres. Residual porque a saúde, a educação e a seguridade social transformam-se cada vez mais em mercadoria, excluindo aqueles que não tem poder 
aquisitivo para comprá-las. Como lembra Ladislau Dowbor, o mercado dos serviços de saúde nos EUA já representa hoje cerca de 14\% do PIB.

Trata-se de uma desconstrução do interesse público e dos direitos de cidadania. Interesse público e direitos construído e conquistados a duras penas por décadas de mobilização social. No limite, trata-se da desconstrução das conquistas democráticas, que em cada contexto histórico efetivo submeteu a lógica do mercado à lógica da afirmação de direitos econômicos, sociais, culturais e ambientais, tais como definidos pelas Cúpulas Sociais dos $\operatorname{anos} 90$.

Essa desconstrução é uma ação política da maior importância. Ela opera uma conversão nos significados dos termos e, na nova matriz discursiva neoliberal, transforma as demandas por direitos em carências. A arena pública e a política são substituídas pelas iniciativas de boa vontade do setor privado e do voluntariado, transformando as ações de afirmação de direitos em filantropia e assistencialismo.

Não é preciso dizer que neste contexto qualquer discurso de crítica ao modelo atual é visto como uma ameaça à hegemonia do pensamento neoliberal, como uma ameaça às forças políticas dominantes, e combatido abertamente. A expectativa por parte dos governos é a do consentimento passivo dos cidadãos. E para realizar esta expectativa combinam-se ações repressivas com a disputa de significados, com a disputa ideológica.

A dimensão repressiva sobre os críticos das políticas neoliberais é de mais fácil compreensão. Basta observar que as manifestações de oposição são desconsideradas em seu conteúdo e tratadas como caso de polícia. As reuniões da OMC, do FMI, do Banco Mundial, tornaram-se eventos cercados por forças policiais e de segurança, criando situações concretas de verdadeiro Estado de Sítio nas localidades em que ocorrem e nem mesmo assim impedem que milhares de manifestantes atuem perante a opinião pública mundial na denúncia das políticas neoliberais. Novos movimentos sociais internacionais tomaram as ruas de Seattle, Genova, Praga, e em cada novo evento que reúne as agencias multilaterais que impõem o Consenso de Washington lá estão eles presentes, reafirmando a necessidade de novos paradigmas de desenvolvimento.

O temor destes organismos multilaterais com respeito aos movimentos sociais de oposição ao modelo neoliberal é justificado. Além das pesquisas de opinião que assinalam uma adesão cada vez maior da opinião pública às bandeiras desses movimentos, existem casos 
concretos de vitórias destes movimentos que bloquearam iniciativas políticas destes organismos multilaterais.

Talvez o caso mais importante tenha sido a denúncia do Acordo Multilateral de Investimentos, preparado durante anos por representantes de empresas transnacionais junto à Organização Mundial do Comércio, a OMC. Este acordo previa a indenização das empresas transnacionais pelos governos sempre que a mudança de políticas públicas redundasse em lucros cessantes ou prejuízos. A denúncia por uma ong do acordo que estava sendo preparado na surdina, o enorme impacto dessa denúncia na opinião pública e em alguns parlamentos europeus, fizeram com que a OMC recuasse e desistisse, em 1998, de propor a política em questão. Esse evento trouxe para a discussão pública a importância que adquiriram as corporações transnacionais, estes novos senhores do mundo, que passam a impor aos Estados e às agências multilaterais sua agenda, seus interesses. ${ }^{2}$

Quanto à repressão sobre os movimentos sociais nacionais que se manifestam pela defesa do emprego, de seus salários, ou de melhores condições de vida; que se manifestam contra as políticas neoliberais; basta observar como atuou o governo brasileiro, nos anos 90, contra as mobilizações do sindicalismo combativo, os movimentos dos sem-terra, as mobilizações do funcionalismo público, as mobilizações dos movimentos sociais urbanos. Suas demandas não foram atendidas, seus discursos desqualificados, suas mobilizações muitas vezes reprimidas.

O exemplo emblemático desta política repressiva no Brasil é dado pela forma como o governo brasileiro tratou a greve dos petroleiros de 1995. O Tribunal Superior do Trabalho declara a greve ilegal - e pune os 21 sindicatos com uma multa de $\mathrm{R} \$ 100$ mil por cada dia dos 21 em que a decisão foi desrespeitada. E a cobrança judicial, além de determinar o bloqueio das contribuições sindicais (R \$ 80 mil mensais no caso de Cubatão) e das contas bancárias, ainda determinou a penhora de todos os bens. O objetivo do governo, claramente, foi de desarticular a capacidade de pressão dos petroleiros

Mas os enfrentamentos não se dão somente nas praças públicas. Eles se dão também - e talvez principalmente - no campo da produção de conhecimentos, na disputa de significados, na determinação do campo dos conflitos, na configuração do que queremos

\footnotetext{
${ }^{2}$ Maude Barlow, Chair of the Council of Canadians, said: "Trans-national corporations have now become so large and powerful that they have replaced nation-states as the defining power structures of the global economy... Small wonder that the heads of state of the world's nations now come cap in hand each year to the World Economic Forum in Davos, Switzerland, to plead with the most powerful corporate leaders to favour their countries with investments. They are all too aware - even if they will not let their citizens in on the secret - that, while they may govern, they no longer rule.
} 
como futuro. E nunca é demais lembrar que quando se tem o poder, é possível também orientar a produção das idéias.

E para que isso se dê é mister desenvolver uma capacidade cada vez mais ágil de resposta às críticas ao neoliberalismo e, ao mesmo tempo, buscar desarticular a capacidade de produção de conhecimento das instituições e movimentos sociais que possam elaborar um pensamento crítico, autônomo; de busca através da criação, das inovações, de caminhos alternativos, de outras propostas de políticas, outros paradigmas para o desenvolvimento.

Temas como o do Terceiro Setor, das empresas com responsabilidade social, das alianças e parcerias, são exemplos destas respostas que influenciam o campo da disputa de significados e enraizaram-se no discurso de muitos que antes se reconheciam por outras identidades. Conceitos como os de desenvolvimento local, participação cidadã, inclusão social, empoderamento da sociedade civil, foram sendo criados ou resignificados também, ganhando contornos mais compatíveis com a matriz discursiva de agencias multilaterais governos e empresas, que deles se apropriam e com eles se apresentam como atores cada vez mais comprometidos com a solução dos problemas sociais.

A dificuldade está em compreender o alcance e as conseqüências desse novo discurso. A questão é "como nos referenciar em um mundo que não lhe cessa de falar de "cidadania" e lhe retira o pouco poder de que você dispõe em seu trabalho e na sua vida?". 3

Esse novo léxico não é nacional. Ele foi criado como uma resposta ao acirramento da crise social. Crise esta que decorre do aumento da desigualdade e da deterioração das condições de vida em sociedade na grande maioria dos países do mundo.

A radicalização dos movimentos internacionais e nacionais de contestação ao modelo de globalização dos mercados levou, por sua vez, a uma crise de legitimidade das instituições políticas e de governabilidade. Essa situação passou a ameaçar a estabilidade política das classes dirigentes e a continuidade política do modelo neoliberal, o que pôde ser visto pelas sucessivas crises que abalaram o México, o Brasil e a Argentina, para ficarmos apenas na América Latina e nos anos 90.

Nas palavras de um dos teóricos do chamado Terceiro Setor - Jeremy Rifkin - essa crise social e de legitimidade política dos governos precisa ser respondida o quanto antes. E aí entra o papel de novas propostas, como a da criação das alianças e parcerias no interior da sociedade civil, vistas como cada vez mais importantes. Isto porque "se o chamado 
Terceiro Setor não ocupar esse espaço de gerar respostas para se enfrentar a crise social será praticamente impossível tratar delas (das questões sociais) daqui a dez anos. Vozes de raiva, de desespero e do ressentimento serão tão fortes que unicamente as ideologias políticas extremas terão êxito". 4

Esse apelo de Rifkin é secundado por ninguém menos que o presidente do Banco Mundial - James Wolfensohn - que em sua fala anual aos governadores do Banco, em 1997, adverte para os riscos do aprofundamento da pobreza e da desigualdade:

"Este - o desafio da inclusão - é o principal desafio do desenvolvimento em nossa era...Os senhores e eu e todos nós nesta sala - os privilegiados no mundo industrial e em desenvolvimento - podemos optar por ignorá-lo. Podemos concentrar-nos apenas nos sucessos. Podemos viver com um pouco mais de crime, com algumas guerras a mais, com ar um pouco mais poluído. Podemos nos isolar de partes inteiras do mundo para as quais a crise é real e diária mas que para o resto de nós é em grande parte invisível. Mas devemos reconhecer que estamos vivendo com uma bomba-relógio e que se não tomarmos medidas agora ela pode explodir na face dos nossos filhos". 5

De fato, depois das crises políticas que se sucederam em vários países nos anos 90 em decorrência da falência do modelo neoliberal, a questão da estabilidade política dos regimes e governos ganha mais importância, abrindo campo para a construção de uma nova agenda social mundial e a elaboração de novos discursos como o do combate à pobreza, o da good governance, o do fortalecimento institucional de governos e instituições da sociedade civil; e, nas palavras do Banco, da promoção de parcerias e coalizões baseadas na cooperação de todos: Nações Unidas, governos, entidades multilaterais, setor privado e sociedade civil.

Esse processo de aggiornamento dos discursos das agencias multilaterais e das Nações Unidas parece ter início já nos anos 70 e, desde então, suas respostas às críticas ao neoliberalismo têm se tornado cada vez mais ágeis.

“Em 1972 o Clube de Roma adverte que o crescimento ilimitado levará à destruição do planeta, o Banco Mundial reconhece e valida esta crítica e produz a teoria do desenvolvimento integrado. O grupo de pesquisadores coordenado por Gro Brundtland e

\footnotetext{
${ }^{4}$ RIFKIN, Jeremy; "Identidade e natureza do Terceiro Setor"; citado por CACCIA BAVA, Silvio; "O Terceiro Setor e os desafios do Estado de São Paulo para o Século XXI”; in Cadernos Abong, n 27; maio de 2000.

${ }^{5}$ James D. Wolfensohn, Presidente do Grupo do Banco Mundial; "O Desafio Da Inclusão"; Discurso à Assembléia de Governadores; HongKong, China, 23 de setembro de $1997 . .^{5}$
} 
Willy Brandt, a seguir, critica o economicismo do Banco, reivindicando outros parâmetros para medir o desenvolvimento, tais como saúde e educação. E o Banco reage apresentando a teoria do desenvolvimento humano. Num novo momento o movimento ecológico ganha importância e influência em toda a Europa e América do Norte, sua critica é sobre as conseqüências presentes e futuras da ação econômica sobre o meio ambiente. Os ideólogos da Banco produzem a teoria do desenvolvimento sustentável. Em 1993, na Conferência sobre Direitos Humanos, em Viena, as nações do Terceiro Mundo - contra os americanos e certos países europeus - impõem o reconhecimento dos direitos econômicos, sociais e culturais. O Banco se coloca na vanguarda do combate pela realização dos direitos econômicos, sociais e culturais, o que pode ser comprovado em setembro de 2000 , pelo discurso de seu presidente em Praga". 6

É importante observar, para fins de nossa discussão, que esses e outros temas foram o foco dos discursos anuais de Wolfensohn dirigidos aos governadores do Banco Mundial. Em 1995, o desafio do desenvolvimento; em 1996, a importância da geração de conhecimentos e do combate à corrupção; em 1997, o desafio da inclusão social; em 1998, o combate à pobreza e a redução das disparidades sociais; em 1999, o tema das parcerias e coalizões; em 2000, o tema da participação cidadã e da criação e disseminação do conhecimento.

Este último tópico - o da criação e disseminação do conhecimento - é especialmente importante para discutirmos a questão da agenda social mundial não só porque mobiliza recursos sem paralelo, mas porque cria uma referência internacional que até o momento não tem um "alter ego" crítico. ${ }^{7}$ Talvez o Fórum Social Mundial esteja buscando tornar-se esta referência crítica, assim como nos anos 90 os Fóruns Globais, organizados pela sociedade civil quando da ocorrência da Rio 92 e das demais conferências mundiais promovidas pelas Nações Unidas, tentaram fazê-lo. Mas o FSM não produz conhecimentos, apenas publiciza e debate as análises que se fazem no campo da sociedade civil.

Todos esses temas que foram objeto de atenção dos discursos do Presidente do Banco Mundial fazem atualmente parte da agenda social das ONGs latinoamericanas, pode-se

\footnotetext{
${ }^{6}$ ZIEGLER, Jean; "Portrait de groupe à la Banque Mondiale"; Le Monde Diplomatique; octubre 2002; pg. 32/33.

${ }^{7} 5$ The Bank Group's relationships with governments and institutions all over the world, and our unique reservoir of development experience across sectors and countries, position us to play a leading role in this new global knowledge partnership. (discurso de 1997)
} 
mesmo arriscar a hipótese de que façam parte da agenda social global das ONGs. E como se dá a ligação entre os discursos de Wolfensohn e a agenda social das ONGs?

Evidentemente a questão da agenda social mundial é de uma importância e uma abrangência muito maior que sua influência sobre as ONGs. Ela de fato pretende pautar a produção do conhecimento na análise das questões sociais e o campo no qual a disputa de alternativas define também o campo do conflito social. Como vem ocorrendo, toda essa produção de respostas às pressões da sociedade se orienta para dissociá-las das políticas macro-econômicas, dos processos históricos e dos interesses nacionais e internacionais em conflito, em cada caso concreto. Para isso concorrem as agencias das Nações Unidas, mas é preciso reconhecer o papel de destaque que vem assumindo nos últimos anos o próprio Banco Mundial.

As análises dos principais organismos das Nações Unidas, como é o PNUD, por exemplo, são indicativas desta nova abordagem. O impacto de suas publicações anuais que avaliam o estado do mundo é enorme. E conceitos como o desenvolvimento humano e sustentável, ou as análises de Amartya Sen, passam a estar presentes em todas as discussões que envolvem a busca de novos paradigmas para a configuração das sociedades futuras.

Todo ano o Banco Mundial publica seu "World Development Report" (o relatório sobre o desenvolvimento do mundo), publicação que se torna referencia obrigatória nos meios universitários e nas Nações Unidas. Essa publicação tem o propósito de fixar os grandes temas que, durante um certo tempo, ocuparão as agências especializadas da ONU, as universidades e, mais além, a opinião pública.

Essa agenda social mundial, segundo Pierre Bordieu, é composta de "lugares comuns - no sentido aristotélico das noções ou teses com as quais se argumenta, mas que sobre as quais não se argumenta nunca - que devem o essencial de sua força de convicção ao prestigio do lugar do qual emanam e ao fato de que circulando intensamente, de Berlim a Buenos Aires e de Londres a Lisboa, estão presentes simultaneamente por todos os lados. De fato, esses pensamentos são retransmitidos com força por todos os lados por estas instancias pretensamente neutras do pensamento neutro que são os grandes organismos internacionais: Banco Mundial, Comissão Européia, Organização para a Cooperação e o Desenvolvimento Econômico (OCDE). No que são secundados pelos laboratórios das idéias conservadoras (Manhattam Institute, de Nova Iorque; Adam Smith Institute, de Londres; Fondation Saint Simom, de Paris; Deutsche Bank Foundation, de Frankfurt), 
pelas instituições de filantropia, pelas escolas de poder (Institut d'Études Politiques, na França; London School of Economics, na Inglaterra; Harvard Kennedy School of Government, nos EUA, etc) e pelos grandes órgãos de imprensa"8.

Em recente artigo no Le Monde Diplomatique, Jean Ziegler atribui aos ideólogos do Banco Mundial um infatigável trabalho de multiplicar teorias justificativas que, segundo ele, ao mapearem o campo do conflito e identificarem as principais críticas e demandas da sociedade, as trabalham e as transformam em propostas dissociadas de qualquer historicidade que, no entanto, passam a ocupar o espaço do debate público sobre as questões sociais.

Como compreender este jogo de poder, como interpretar esta disputa de significados e seu impacto sobre as instituições de produção do conhecimento, como identificar os processos que fazem com que essa agenda que se constrói neste jogo de forças internacional seja assumida pelas ONGs?

Talvez a chave que nos permita a compreensão de todo esse processo nos tenha sido dada por Ziegler e Bordieu, quando eles identificam o papel destas agencias internacionais e especialmente o papel que vem assumindo o Banco Mundial como produtores de ideologia. Ideologia é aquilo que tem por função, ao se impor como discurso racional, de impedir a interrogação sobre os fundamentos, a legitimidade e a evolução da ordem social, como nos ensina Claude Lefort.

Por esta via de explicação as causas do aprofundamento da pobreza e da desigualdade no mundo são deixadas de lado, a globalização dos mercados nos moldes do Consenso de Washington passa a ser compreendida como um processo inexorável, as políticas possíveis para se enfrentar as mazelas do mundo são as apontadas em uma agenda social mundial para a qual a contribuição do Banco Mundial tem um papel determinante.

E por que o Banco Mundial, que é antes de mais nada um banco, teria tanto interesse em produzir análises e propostas que busquem organizar o debate público mundial em torno de um certo enfoque sobre as alternativas de desenvolvimento e a superação da crise social?

Este complexo jogo da disputa dos significados faz parte de um jogo mais amplo de poder, conforme nos adverte Francisco de Oliveira: "Impor a agenda não significa necessariamente ter êxito, ganhar a disputa; antes, significa criar um campo específico 
dentro do qual o adversário é obrigado a mover-se. É evidente que o adversário, em seus movimentos, tenta, por sua vez, desvencilhar-se da pauta e sair fora da agenda que lhe é oferecida/imposta. É nesse intercâmbio, desigual, que se estrutura o próprio conflito, ou o jogo da política. Há, pois, na política, uma permanente mudança de qualidade. A força de uma invenção se expressa na capacidade de manter o adversário nos limites do campo criado pela proposta/resposta, e isto confere estabilidade ao campo político, permanecendo a pauta e a agenda das questões". 9

É inegável que na atual conjuntura a agenda social mundial tem sido mantida e renovada nos termos de complementariedade aos programas de ajuste estrutural das economias dos países pobres, segundo o modelo identificado como sendo o do Consenso de Washington. Mas como se propaga essa ideologia ao ponto da agenda social mundial que dela decorre ser assumida pelas ONGs do Sul?

Aqui cabe referir a importância das redes de instituições que se conectam e interagem seja na produção da agenda social mundial, seja no financiamento dos trabalhos das ONGs do Sul. Essa cadeia de relações é assimétrica, possui elos mais fortes e elos mais fracos.

No seu lado mais forte estão as instituições multilaterais que contam com vastos recursos intelectuais, financeiros e de comunicação. Entre elas se destacam o Banco Mundial, organismos vários das Nações Unidas, a Comissão Européia. Ainda nesta parte mais forte da cadeia de relações com as ONGs estão os governos nacionais dos países desenvolvidos (cada vez mais conservadores), que interagem, influenciam e são influenciados pela produção e pelas propostas das agencias multilaterais. É preciso referir aqui que a postura dos governos dos países do Sul é, na maioria esmagadora dos casos, de aceitação e complementariedade às políticas geradas por estas organizações multilaterais.

No elo mais fraco desta cadeia estão as ONGs do Norte e do Sul. Os governos nacionais dos países desenvolvidos exercem uma influencia crescente sobre as ONGs do Norte, agencias privadas de cooperação existentes em seus países e que dependem cada vez mais dos recursos públicos repassados pelos seus governos. Neste elo mais fraco estão as ONGs do Sul, dezenas de milhares de ONGs que dependem dos recursos financeiros do Norte e, pelas limitações da própria agenda internacional, que por exemplo não financia pesquisas, não têm conseguido desenvolver análises críticas da realidade social e da produção teórica que orienta a construção da agenda social global.

${ }^{9}$ OLIVEIRA, Francisco de; "Política numa era de indeterminação: opacidade e reencantamento"; paper; São Paulo; 2002. 
Em um texto recente Bebbington chama a atenção de que este tema é bem mais abrangente, trata da relação entre o poder e a comunicação (à la Habermas), ou entre o poder e o conhecimento (à la Foucault). "De Habermas (1984) temos a idéia de que não há nenhuma forma de comunicação que não seja distorcida pelas relações de poder; e de Foucault (1980) temos a noção de que existem relações de poder inscritas em toda forma de conhecimento". 10

Em um recente estudo promovido pela Associação Latinoamericana de Organizações de Promoção - ALOP, uma das mais importantes redes de ONGs de Desenvolvimento, a questão da fragilidade das ONGDs enquanto um elo da cadeia de instituições do mundo da cooperação é reconhecida e identificada como uma limitação dada pelas dificuldades de desenvolver uma análise crítica da realidade social e de produzir propostas alternativas. Para isso consideram como uma das mais importantes necessidades reforçar sua capacidade de pesquisa e sistematização.

"Hoje torna-se evidente a necessidade de recolocar a questão dos paradigmas do desenvolvimento e de pensar novas estratégias para enfrentar realidades mais complexas...em muitos casos será necessário reconceituar os temas, independentemente dos marcos utilizados pelos modelos imperantes...há temas que são tratados isoladamente do seu contexto, como o da pobreza; outros que desapareceram da agenda social e que precisam ser retomados, como o da concentração da riqueza ou o das estruturas nacionais e regionais de poder..." 11

Essa proposta de pensar novas estratégias, de buscar reconceituar certos temas e reintroduzir outros no debate, de questionar os paradigmas impostos por uma agenda de desenvolvimento, tem a maior importância. Ela permite sair do campo previamente demarcado do debate, do conflito, e criar um novo campo de disputas onde os termos do debate possam ser de nova qualidade, introduzindo questões como a redistribuição da riqueza e a socialização do poder, ou como diz Boaventura de Souza Santos, a democratização da democracia.

Estas novas propostas são essenciais para que as ONGs possam superar esta zona cinzenta de indeterminações a que nos referimos no início e atualizar sua dimensão de agentes sociais de mudança. A análise crítica desta agenda social global poderá permitir encontrar

10 BEBBINGTON, Anthony; "Reflexiones sobre la relación Norte-Sur en la construcción de conocimientos sobre las ONGs en America Latina"; paper; ALOP/ABONG; São Paulo; 2001.

11 LEÓN; Mariano Valderrama; "El fortalecimiento institucional y los acelerados cambios en las ONGD latinoamericanas"; in ALOP; "La sostenibilidad de las ONG latinoamericanas"; CEPES; Lima; 2000. 
novos caminhos para recuperar a esfera pública e a política como espaço da resolução dos conflitos sociais; poderá permitir mapear e identificar quais os atores sociais que podem configurar um campo efetivo de alianças na perspectiva da mudança social e quais atores sociais que hoje se apresentam como "parceiros", mas que de fato não o são. E para isso as ONGs terão de se perguntar qual a sua agenda e quem são seus pontos de apoio, que atores coletivos estimulam e defendem seus temas...

Com base nestas referências e na perspectiva de discutir os limites e possibilidades de nossa agenda social, serão tratados a seguir os temas desenvolvimento local, inclusão social e participação cidadã.

\section{O Mito do Desenvolvimento... Local}

Durante os últimos 50 anos o mito do desenvolvimento alimentou a esperança de mais de 3/4 da população do mundo. Ele acenava com a possibilidade de que os países pobres pudessem tornar-se sociedades com altos padrões de vida, sociedades desenvolvidas, à semelhança dos 24 países capitalistas industrializados.

Este mito precisa ser questionado. Não faltam dados que permitam este questionamento. A história recente da humanidade atesta a impossibilidade do desenvolvimento para os países pobres. Ao menos nas condições atuais de organização da produção e dos mercados, de acordo com o modelo atual da globalização. Ao invés de trazer o desenvolvimento, este modelo se revelou promotor da exclusão social, acelerado nas últimas décadas pelo desenvolvimento tecnológico e pelo neoliberalismo.

Hoje, os $20 \%$ dos seres humanos que vivem nos países mais ricos consomem $86 \%$ dos bens produzidos pela humanidade. Os $20 \%$ que vivem nos países mais pobres não consomem mais do que $1,3 \%$ do total. E o mais importante a observar foi a acelerada tendência à concentração da renda e aumento da pobreza verificada nas últimas décadas. Em 1960 a diferença de renda entre os $20 \%$ mais ricos e os $20 \%$ mais pobres era de 30 para 1. Em 1995 essa diferença atinge a proporção de 82 para 1.

Pode-se caracterizar uma verdadeira regressão na qualidade de vida das maiorias, notadamente no Sul, mas também nos países do Norte. Abandonando os critérios de renda média e utilizando-se de uma metodologia que revela as desigualdades no interior de cada país, o PNUD pôde demonstrar que nos países industrializados existem hoje mais de 100 
milhões de pessoas em situação de pobreza e com grandes problemas de moradia. A porcentagem de pobres varia de $7 \%$ a $17 \%$ da população total nestes países.

Mas a tendência ao crescimento da pobreza e da exclusão se apresenta com toda a força e intensidade nos países do Sul, países que se tornaram cada vez mais dependentes e vulneráveis à dinâmica do mercado global, à mobilidade especulativa do capital financeiro, à atuação das empresas transnacionais, ao protecionismo imposto pelos países mais industrializados às suas indústrias e ao seu mercado.

De fato, o que os dados revelam é que está ocorrendo nos últimos 30 anos uma regressão econômica nos países do Sul que afeta significativamente a qualidade de vida de grande parte da sua população. Na África, por exemplo, o consumo de uma família hoje é $20 \%$ menor que 25 anos atrás. Mais de 100 países dentre aqueles considerados subdesenvolvidos ou em vias de desenvolvimento apresentaram uma queda na sua renda per capita no curso dos últimos 30 anos. Nada menos que 3 bilhões de pessoas, dos 4,4 bilhões que habitam esta região do planeta, vivem hoje com menos de US\$2,00 por dia, considerado pelas Nações Unidas como o mínimo para a sobrevivência. ${ }^{12}$

Este modelo chega hoje ao extremo da promoção da desigualdade. A soma dos bens das 300 pessoas mais ricas do mundo é igual ao total dos bens dos 2,7 bilhões de seres humanos mais pobres, algo como $45 \%$ da população mundial. Os indivíduos que tem condições de consumir produtos e serviços são cerca de 1,8 bilhões. Os 4 bilhões remanescentes não possuem capacidade de compra, estão fora do mercado. ${ }^{13}$

Esta realidade é ignorada pela ideologia do desenvolvimento, que continua a acenar com a possibilidade de um futuro brilhante para os países agora chamados de "emergentes". No que se sustenta esta ideologia? Como explicar que continue tendo o poder de fascinação que ainda hoje mantém?

A base em que se apóia a noção de desenvolvimento é a idéia de que o progresso é inerente às sociedades agrárias que transitam para sociedades industriais. Um tipo de darwinismo evolucionista que assegura a toda e qualquer sociedade um futuro promissor. Algo que poderia estar em seu DNA. O desenvolvimento da indústria, da tecnologia, da produtividade, assegura o progresso. E o progresso tem um sentido único: ele leva ao desenvolvimento, entendido como o reino da abundância, do consumo.

\footnotetext{
${ }^{12}$ Dados citados em CACCIA BAVA, Silvio; “O Terceiro Setor e os desafios do Estado de São Paulo para o século XXI”; Fórum São Paulo Século XXI; Assembléia Legislativa do Estado de São Paulo; 1999.

${ }^{13}$ RIVERO, Oswaldo; “The mith of development”; Zed Books; London; 2001; p. 110.
} 
Um grande promotor do mito do desenvolvimento foi Walter Rostow, professor do Massachusets Institute of Technology. Nos anos 60 ele afirmou que "os países evoluíam de uma sociedade tradicional, através de estágios de acumulação e de crescimento de suas economias, para atingir um estágio final de consumo de massa, o qual ele identificava como sendo a conquista do desenvolvimento. Segundo ele, o ambiente no qual se dava este desenvolvimento não tinha importância neste processo, seria apenas a matéria-prima a ser consumida na marcha para o progresso e a felicidade. Depois de Rostow, todos tecnocratas convenceram-se que podiam conquistar o desenvolvimento. Eles somente necessitavam saber como aplicar corretamente as teorias e políticas, criar valor agregado, acumular, crescer e induzir ao consumo de massas". ${ }^{14}$

A crítica à noção de desenvolvimento elaborada por Marilena Chauí aponta que esta noção "visa escamotear a história sob a aparência de assumí-la... pressupõe-se um ponto fixo, idêntico e perfeito, que é o ponto terminal de alguma realidade e ao qual ela deverá chegar normativamente. O progresso, colocando a larva, e o desenvolvimento, colocando a "boa forma" final, retiram da história aquilo que a constitui como história, isto é, o inédito e a criação necessária de seu próprio tempo e telos. Colocando algo antes do processo (o germe) ou depois do processo (o desenvolvido), a ideologia tem sérios compromissos com os autoritarismos, uma vez que a história de uma sociedade passa a ser regida por algo que ela deve realizar a qualquer preço. Passa-se da história ao destino". ${ }^{15}$

Durante o período da guerra fria este mito do desenvolvimento serviu como propulsor de uma política de controle de territórios e mercados - a disputa entre o bloco soviético e os países capitalistas industrializados pela hegemonia mundial. A questão da ajuda para o desenvolvimento tornou-se um dos principais eixos da geopolítica mundial, estendendo-se esta disputa para regiões como a África e a América Latina. O Banco Mundial (fundado em 1944), que leva o nome de Banco Internacional para a Reconstrução e o Desenvolvimento, assim como bancos regionais como o Banco Interamericano de Desenvolvimento (fundado em 1959) e o African Development Bank (fundado em 1964) são criados como poderosos instrumentos de uma política de consolidação dos interesses deste bloco de países capitalistas industrializados, liderados pelos Estados Unidos.

Num certo sentido pode-se dizer que as políticas preconizadas pelo Consenso de Washington são herdeiras e atualizam o mito do desenvolvimento. O fim da guerra fria e a

\footnotetext{
${ }^{14}$ RIVERO, Oswaldo; "The mith of development”; Zed Books; London; 2001; p. 110.

${ }^{15}$ CHAUÍ, Marilena; "Conformismo e Resistência - aspectos da cultura popular no Brasil”; Ed. Brasiliense; São Paulo; 1986; p30.
} 
subordinação das instituições multilaterais às políticas ditadas pela única superpotência mundial reduziram substancialmente a importância da "ajuda para o desenvolvimento", que hoje chega ao seu ponto mais baixo, representando algo como 0,20\% do PIB dos países industrializados, quando na Rio 92 estes países assumiram o compromisso de comprometer $0,70 \%$ de seu PIB nesta rubrica. ${ }^{16}$ Esta política se torna agora dispensável como instrumento no jogo pelo poder e controle dos territórios do tabuleiro mundial, como nos lembra Susan George. Estratégia esta substituída pela política de endividamento crescente dos países "emergentes", a partir dos anos 80 , que por esta razão tiveram uma redução substancial em sua capacidade de elaborar suas próprias estratégias de desenvolvimento.

Neste cenário reduz-se brutalmente a margem de negociação dos países pobres, que se viram obrigados, pela via da necessidade de reestruturação de suas dívidas junto ao FMI e ao Banco Mundial, a adotarem ajustes e políticas macroeconômicas que abriram enormes oportunidades de ação para as grandes corporações transnacionais do Norte e reduziram dramaticamente o papel do Estado, particularmente nos setores sociais e agrícola. Os programas de ajuste conduziram à privatização de importantes setores da economia, assim como à liberalização do comércio e das regulações bancárias, apontando a um crescimento baseado nas exportações, muitas vezes em detrimento da industria local e do meio ambiente. $^{17}$

No final dos anos 90 se reconhecia amplamente que as receitas inspiradas no Consenso de Washington, e impostas a tantos países em desenvolvimento, estavam eivadas de sérios erros. As crises econômicas e políticas sucessivas que ocorreram nos anos 90 em países que seguiram fielmente a cartilha do Consenso de Washington - entre os quais Indonésia, Rússia, Coréia do Sul, México, Brasil e Argentina - são um alerta para todos, inclusive para o Banco Mundial, que reelabora sua doutrina à luz das críticas e das crescentes manifestações de massa contra a implementação deste modelo.

Um dos resultados deste processo de reelaboração do mito do desenvolvimento é a proposta do desenvolvimento local, ou mesmo da possibilidade, no mundo globalizado, de que ilhas de excelência existentes nos países pobres, como as cidades de São Paulo ou Buenos Aires, por exemplo, possam se tornar global players, independentes da dinâmica dos Estados nacionais.

\footnotetext{
${ }^{16}$ EARTHSCAN; "The reality of aid 2000"; Earthscan publications; London; 2000.

${ }^{17}$ ALOP; "Mito y realidad de la ayuda externa: América Latina al 2002"; ALOP; Lima; 2001; p. 31.
} 
A impossibilidade do desenvolvimento comprovada pelo diagnóstico do desempenho dos países pobres nos últimos 30 anos levou a novas formulações que evitam as abordagens macro-estruturais e remetem a questão do desenvolvimento para o domínio dos governos locais e para políticas de combate à pobreza.

"É muito evidente que o tema do desenvolvimento local vem sendo colocado na agenda da discussão político-econômico-social e cultural devido ao fracasso das abordagens macroestruturais em romper, no plano social com a desigualdade, no plano econômico com a concentração do poder, no plano político com a declarada insuficiência dos mecanismos e processos da democracia representativa e no plano cultural com a folclorização trabalhada pela "indústria-cultural" como exotismo..."comenta Francisco de Oliveira, que ao reconhecer a introdução do tema do desenvolvimento local na agenda social mundial, pergunta: "o nível local resistirá às avalanches globais, quando mesmo o Estado-Nação dá mostras de cambalear diante delas, para não concordar com o "sucumbir" que já está na maioria dos discursos sobre a globalização?"18

De fato, pela força de penetração desta agenda social mundial, a questão do desenvolvimento local foi incorporada à agenda de múltiplos atores sociais e tem se transformado em um dos principais temas de discussão, pesquisa, e mesmo de intervenção por parte de: governos municipais, agências estatais de desenvolvimento, ongs, universidades. E novamente aí a disputa em torno do significado dos conceitos, agora o de desenvolvimento local, desenha distintos horizontes, limites e possibilidades.

O Instituto Pólis, uma ong brasileira que trabalha os temas da participação cidadã, das políticas públicas urbanas e dos governos locais, tem realizado a sistematização de experiências e o debate sobre o alcance destas iniciativas identificadas como sendo de desenvolvimento local desde 1995. E pôde constatar que sob a denominação genérica de experiências de desenvolvimento local se abriga uma ampla gama de iniciativas que, em sua maioria, mobilizam escassos recursos, buscam incidir tanto na área social quanto na econômica, e ainda estão por ser analisadas quanto ao efetivo impacto que produzem no ambiente local. Mas mesmo sem essa análise mais acurada de resultados é possível dizer que as experiências estudadas não alteram o quadro geral de desigualdade social e da pobreza local.

${ }^{18}$ OLIVEIRA, Francisco de; Proposta para discussão sobre desenvolvimento local: limites e possibilidades; paper; Instituto Pólis; São Paulo; 2000. 
Caracterizadas muito mais como um experimentalismo difuso, estas iniciativas consistem em projetos de "microcrédito, verticalização da agricultura, incubadoras, programas de marketing municipal, agências de desenvolvimento, consórcios intermunicipais, apoio à agricultura familiar, políticas de atração de investimentos, intervenções em cadeias produtivas e sistemas locais de produção, capacitação de empreendedores e outros atores, criação de infra-estrutura e intervenções urbanas". ${ }^{19}$

Num certo sentido, pode-se afirmar que a grande maioria dos agentes que impulsionam as iniciativas de "desenvolvimento local" o fazem não no sentido da complementariedade a projetos de desenvolvimento nacional, mas justamente porque este está ausente, pela falta de respostas das políticas nacionais ao acirramento do desemprego e da crise social no plano local.

A tentativa de tornar o "desenvolvimento local" um modelo paradigmático de solução dos problemas que a sociedade mais inclusiva não consegue solucionar é nada mais que a reedição do mito do desenvolvimento. E, como já apontado anteriormente, esta iniciativa desconhece a história, desterritorializa as experiências e ignora a importância dos atores locais portadores de distintos projetos e interesses. A proposta pensa o local como um território homogêneo, uma comunidade com interesses comuns que, ao somar seus esforços, consiga dar conta do desafio de enfrentar os problemas sociais que se acumulam. Como se no plano local não se reproduzissem os mecanismos de poder e os interesses das elites que, traduzidos na forma de políticas públicas, são os promotores da desigualdade social e da pobreza.

A possibilidade do desenvolvimento local é ainda questionada pelo perfil da ocupação do território, principalmente nos países do Sul, onde a explosão urbana é uma realidade e a concentração da maior parte da população se dá em regiões metropolitanas nas quais a maioria integra o setor informal, o Estado se torna cada vez mais ausente e já não controla todo o território, a violência e a criminalidade crescem assustadoramente.

Os trabalhos de pesquisa mais recentes do Instituto Pólis, reconhecendo as limitações em termos de resultados, isto é, da conquista de um efetivo desenvolvimento local a partir destas iniciativas em curso, apontam, no entanto, para uma nova forma de interpretação destas experiências ao recuperar sua dimensão histórica: “...a capacidade de mobilização e articulação de atores sociais aparece como uma dimensão fundamental, indicando que os

\footnotetext{
${ }^{19}$ FRANÇA, Cassio Luiz de; SILVA, Ivan Prado; VAZ, José Carlos; "Aspectos Econômicos de Experiências de Desenvolvimento Local”; Revista Polis número 40; Instituto Polis; São Paulo; 2002; p. 7.
} 
aspectos sociais e políticos desempenham um papel chave nos resultados econômicos...o que parece corroborar a idéia de que as iniciativas locais necessitam reconhecer a existência de interesses distintos e conflitos latentes ou potenciais..."20

Esta análise se contrapõe à idéia ingênua de que o desenvolvimento local seja uma possibilidade decorrente de uma conjugação de esforços da comunidade (de um conceito de comunidade na qual seus integrantes não se diferenciam, parecendo que todos têm os mesmos interesses e objetivos), que bastaria impulsionar uma aproximação, uma aliança entre estes atores locais, para que se dessem as condições para o desenvolvimento.

As perspectivas de desenvolvimento local identificadas pelo Instituto Pólis assinalam que é preciso reconhecer a diferenciação dos interesses e objetivos dos distintos atores coletivos da sociedade civil e a dimensão do conflito que está presente em suas relações. A possibilidade de um projeto de desenvolvimento local parece residir em uma percepção dessas diferenças de interesses e objetivos e da adoção de um método de negociações que traga para a arena pública estes interesses em conflito e permita, frente aos casos concretos que se coloquem, o estabelecimento de acordos que se fundem na afirmação do interesse público e na perspectiva da superação das desigualdades sociais e da pobreza.

A questão do desenvolvimento local, desta ótica, adquire uma feição muito mais política que econômica. Trata da possibilidade da inclusão de novos atores coletivos na negociação acerca do que se entende por interesse público e da definição de políticas públicas que contemplem seus interesses e necessidades.

"A questão da participação popular ganha importância porque estes setores populares têm interesses e valores a defender, porque todos têm que poder expressar-se... porque a expressão do conflito nesses novos espaços públicos pode ser positiva, porque a cooperação social é necessária, e os poderes públicos necessitam de interlocutores. E, sobretudo, porque mediante a participação é possível que se expressem os coletivos mais débeis ou vulneráveis, os menos escutados, e é uma responsabilidade dos governos locais dar-lhes a palavra". 21

Construída desta forma, a problematização das possibilidades do desenvolvimento local remete à questão da disputa pela hegemonia entre o modelo de sociedade de mercado e um novo paradigma de sociedade, inspirado num novo humanismo pautado centralmente

\footnotetext{
${ }^{20}$ FRANÇA et allii...op.cit.

${ }^{21}$ BORJA, Jordi; "Participación ciudadana: una cuestión política"; in Revista Foro, n. 45; septiembre 2002; Ed. Foro Nacional por Colombia; Bogotá; p.85.
} 
pelos valores da solidariedade, pela participação cidadã, pela democratização dos governos locais e do espaço público, pela construção de um movimento que se contraponha ao modelo neoliberal e seja portador de projetos que afirmem a universalização dos direitos econômicos, sociais, culturais e ambientais.

De fato, o processo histórico brasileiro tem permitido que nos últimos vinte anos esse novo paradigma venha tentativamente sendo construído a partir da eleição de governantes municipais originados de movimentos sociais e comprometidos com a bandeira da universalização dos direitos.

\section{A questão da participação popular}

A questão da participação popular começa a ocupar a agenda das agências multilaterais quando eclodem as crises dos anos 90 em alguns dos principais países que seguiram à risca o modelo do Consenso de Washington, colocando em risco a estabilidade política dos governos e, em alguns casos, subtraindo ao controle das elites tradicionais o controle da nação.

Estas crises se dão em razão do alto custo social dos ajustes, do aprofundamento da pobreza e da desigualdade, e geram por sua vez crescentes manifestações sociais de protesto seja no interior dos países nos quais ela ocorre, seja no plano internacional, onde vai se estruturando um movimento cada vez mais importante e abrangente de oposição e denúncia do Consenso de Washington e dos organismos internacionais através dos quais ele é imposto.

Os Fóruns Globais organizados pelas ONGs do Norte e do Sul em paralelo às Conferências das Nações Unidas realizadas nos anos 90 demandam substantivamente a participação da sociedade civil organizada nas decisões destas cúpulas mundiais. $\mathrm{O}$ apoio da opinião pública mundial a essas demandas é tal que o tema da participação cidadã passa a estar inscrito na agenda social mundial e exige das agencias internacionais uma reação a estas demandas.

A questão de como enfrentar as mobilizações e as críticas que vem da sociedade civil se torna mais delicada para o Banco Mundial quando, na reunião de comemoração de seus 50 anos, em Madrid, em 1994, ativistas tentam jogar uma torta no rosto de Lewis Preston, presidente do Banco, iniciativa frustrada pelo sistema de segurança, mas que traz a público novas formas de protesto e dá publicidade às criticas do movimento. O Greenpeace e a 
Oxfam apresentam, na oportunidade uma série de informes profusamente documentados sobre os efeitos sociais nefastos das medidas do Banco Mundial e do FMI. A participação de outras entidades como a Rainforest Action Network, da Califórnia, ou a Action for Solidarity, Equality, Environment and Development; dão mostras de novas formas de organização e protesto que irão se ampliar e muito nos anos seguintes, como se verá nas manifestações de Praga, Seattle e Genova, por exemplo.

As avaliações no Banco Mundial sobre estas novas formas de protesto dão margem ao reconhecimento de que é necessário absorver as críticas e reelaborá-las, de maneira a atender as demandas nelas contidas. Segundo seus próprios dirigentes "o risco de desatender ditas inquietudes é o de que estas se convertam em um obstáculo para as instituições globais". 22

O Banco, preocupado, já em 1994 formula uma política de relações públicas para melhorar sua imagem, o que é o início do processo que irá desembocar na produção de uma agenda social mundial e nas propostas de participação e empoderamento associadas ao tema da governabilidade. $^{23}$

A Oficina Regional para a América Latina aprova, em 1999, a primeira Estratégia Regional sobre Sociedade Civil 2000-2001. Nela constam: a inclusão da participação da sociedade civil nos projetos do Banco; a promoção de diálogos incluindo governos, sociedade civil e o setor privado; a produção e divulgação de um crescente número de trabalhos analíticos sobre a participação da sociedade civil.

Em janeiro de 2000 o economista-chefe e primeiro vice-presidente do Banco - Joseph Stiglitz - renuncia a seu cargo e denuncia a estratégia de privatização e a ineficácia do sistema de Breton Woods. Deste questionamento surge uma nova estratégia e um novo organograma do Banco. O Departamento Social, reforçado por novos quadros, deve ser consultado imperativamente por todos chefes de projetos. Este departamento tem por responsabilidade examinar e avaliar as conseqüências humanas e sociais provocadas na sociedade em razão das intervenções do Banco: construção de uma estrada, uma barragem, um porto, um conglomerado industrial, o desvio do curso de um rio, etc.

Esta iniciativa que busca dar maior visibilidade às atividades do Banco e abrí-lo à participação da sociedade civil, resulta efetivamente numa maior participação das ONGs

22 Civil Society Team; "Empoderar a los pobres y Promover la Rendición de Cuentas en LAC"; Oficina Regional Para America Latina y el Caribe; Banco Mundial; 2002; pag. 9.

23 Ver "El Banco Mundial desafía a las ONG" in Tercero Mundo Economico; vol. 52; octubre de 1994 
em consultas sobre os projetos do Banco, mas esta participação não tem poder de alterar as suas políticas. Entretanto, no seu discurso, o Banco "concebe a participação da sociedade civil como um meio de promover o empoderamento". ${ }^{24}$

O Departamento Social, encarregado dos processos de participação, parece ser muito mais peça de uma estratégia de marketing que um órgão que influi nas políticas do Banco. "Este departamento não tem qualquer poder. Mesmo se as conclusões forem inteiramente negativas, mesmo que sejam previstos desastres sobre desastres, ele não poderá impedir a realização do projeto. A decisão dos banqueiros é sempre soberana." 25

A participação da sociedade civil, nestes termos, é vista como uma forma de esvaziar os movimentos sociais e protestos anti-globalização, assim como um meio de reconstruir a imagem das instituições multilaterais perante a opinião pública mundial.

A difusão da agenda social mundial e sua tradução feita por estudos acadêmicos e agencias de cooperação trazem para o meio das ONGs o enfoque da participação associado às estratégias de governabilidade. Não se trata de ampliar a democracia e socializar o poder, como reivindicam os movimentos sociais nas ruas, nos eventos de que participam, na mídia de uma maneira geral. Trata-se, isto sim, de canalizar as demandas sociais para momentos de consulta e formalização destas demandas para que elas sejam processadas por canais institucionais e métodos que garantam o controle da situação e a estabilidade política pelas instituições que organizam esses processos de participação.

Os processos de ajuste estrutural na América Latina levaram a um incremento do autoritarismo por parte dos governos que, nos marcos da democracia formal de baixa intensidade, como a chama Boaventura de Sousa Santos, buscaram desarticular os atores sociais que se opunham ao processo de destituição de direitos e reclamavam por participação.

Neste cenário foram afetados, em diferentes graus, os sindicatos, as associações comunitárias, as ONGs, os movimentos sociais que buscam se expressar nos espaços públicos em defesa dos direitos de cidadania. São múltiplas as iniciativas de governos que visam controlar e silenciar as vozes de oposição e resistência à redução das políticas sociais a políticas compensatórias. No caso das ONGs, tornaram-se notórias as tentativas de aprovação de leis que viessem a centralizar e controlar o repasse de financiamentos das 
agencias internacionais de cooperação às ONGs locais. Em alguns casos, contraditoriamente, estas iniciativas foram barradas com o apoio de agencias multilaterais.

As propostas de participação formuladas pelo BID, pelo Banco Mundial, por agencias das Nações Unidas, neste contexto, se apresentam como identificadas com as demandas da sociedade civil e são importantes para criar uma identidade para estas agências multilaterais com a marca da democracia, da inovação, do compromisso com as demandas e necessidades populares. Ela serve também para diferenciar a direção atual que a implementa dos dirigentes anteriores, já que no plano econômico a marca é o continuísmo nos termos do ideário neoliberal.

O que se observa da análise das experiências é que a participação tem ficado muito aquém das expectativas, quase só no discurso, tornando-se na verdade um exercício ideológico de incorporar as iniciativas populares aos discursos e programas, resignificando-as e, desta forma, buscando promover a cooptação, a manipulação e o controle das forças sociais envolvidas.

Novamente estamos frente a um processo de metamorfose, de resignificação de conteúdos que, na sua origem, na perspectiva de afirmação da cidadania na sua relação com governos, trazem os signos da democratização do Estado e da sociedade, do controle social sobre as formas de gestão pública e as políticas públicas.

Esta perspectiva estratégica original, de transformação democrática, pode ser identificada no projeto do controle público do Estado, explicitado nas seguintes palavras de Tarso Genro: “...um governo orientado para "abrir o Estado", a fim de que, por meio de mecanismos de controle público não-estatal (que vem da base da sociedade), façamos com que o Estado saia da lógica tradicional da democracia formal e fique cada vez mais determinado por essa nova dialética, por essa nova tensão, que é a tensão que vem da sociedade civil organizada: seja por meio dos conselhos populares, seja por meio do controle público do orçamento, mediante o qual se estabelece uma nova relação entre a representação formal (a Câmara de Vereadores), a delegação que resultou na eleição do prefeito e, de outro lado, a ação da democracia direta e estruturada "fora" do Estado. Isso reforma e radicaliza a democracia e sustenta, de fato, os direitos constitucionais dos cidadãos". 26

\footnotetext{
${ }^{26}$ GENRO, Tarso; "Um debate estratégico"; in "Governo e Cidadania: balanço e reflexões sobre o modo petista de governar"; Ed. Fundação Perseu Abramo; São Paulo; 1999; pág. 15.
} 
Se este pode ser compreendido como o sentido transformador do projeto de democratização, é de se reconhecer, no entanto, o impacto e a importância que adquirem hoje esta versão da participação da sociedade civil associada ao projeto de governabilidade.

Ela busca substituir outras matrizes discursivas, como o da disputa pelos recursos públicos e por políticas públicas, como o da mudança social e dos movimentos sociais, e busca a redução do horizonte utópico dos atores sociais levando-os a propor melhorar um pouco o que aí está. A dimensão do conflito social desaparece do campo analítico, as possibilidades de rupturas e a criação de uma nova ordem social saem de cena; estas bandeiras deixam de estar inscritas no horizonte de possibilidades dos atores coletivos subalternos.

Propõe-se uma nova forma de colaboração a partir de hipotéticas alianças que operem no plano local, que aprofundem e qualifiquem os processos de descentralização. As alianças são entendidas principalmente como a mobilização de energias da sociedade civil para a implementação de projetos de governo. A questão das diferenças entre atores coletivos é entendida como diferenças de grau, não de qualidade, o corpo social é visto como um todo sem conflitos, que necessita apenas de um impulso e da boa vontade para promover sinergias.

Ressalte-se que para validar este discurso lança-se mão da divulgação de experiências inovadoras de sucesso, mesmo que beneficiando pequenos grupos, em detrimento de uma análise de contexto que permita o diagnóstico mais abrangente das causas dos problemas sociais e de suas possíveis soluções. Desta forma, o universo de possibilidades para se enfrentar os problemas sociais fica confinado às políticas focalizadas e compensatórias, dirigidas aos grupos mais vulneráveis da sociedade.

No Brasil, esta disputa quanto aos múltiplos significados políticos da participação se dá, na nossa história recente, em distintas frentes de conflito. Já na Constituição de 1988 se afirmam novos direitos de participação cidadã através da instituição de Conselhos de Gestão de políticas específicas com uma configuração paritária entre membros de governo e representantes da sociedade civil e competências deliberativas. Estes Conselhos se afirmam nas áreas de saúde, assistência social, defesa dos direitos das crianças e dos adolescentes e em várias outras áreas com menos importância. Pesquisa recente atesta que são 27.000 os Conselhos de Gestão existentes no Brasil atualmente. 
As experiências de Orçamento Participativo igualmente expressam esse movimento de instituir formas de controle social sobre as políticas públicas e a destinação dos recursos públicos. Atualmente são cerca de 130 cidades brasileiras que implementam o OP.

No Legislativo afirmaram-se direitos como o da requisição por parte da sociedade civil de Audiência Pública para a discussão de projetos de lei, como a possibilidade de apresentação de projetos de lei de iniciativa popular.

Trata-se de uma longa trajetória de instituição de novos espaços públicos e novas modalidades de participação permanentemente atravessadas pelas questões do controle e da autonomia das organizações da sociedade civil.

A mudança recentíssima na conjuntura brasileira, com a eleição de Lula para Presidente da República, é parte e expressão desse processo de mobilização cidadã. Trata-se, ao que parece, de uma oportunidade de reconfiguração das relações de poder, onde o discurso neoliberal hegemônico começa a ser desafiado por um novo projeto político que não tem mais a satisfação das demandas "do mercado" como seu interesse maior, mas pode afirmar o primado de um projeto de radicalização democrática e redução das desigualdades como centro de suas preocupações.

Parecem se abrir no Brasil possibilidades para a elaboração de uma nova matriz discursiva onde a participação da sociedade civil pode ser novamente interpretada como a participação cidadã, como mobilização social transformadora, orientada para a garantia e ampliação de direitos, o que poderá reconfigurar o campo de alianças e parcerias possíveis. A participação popular, da ótica conservadora, é entendida apenas como a integração de representantes da sociedade civil em mecanismos de consulta sobre políticas públicas e se expressa também através da convocação de entidades da sociedade civil para prestação de serviços voluntários e remunerados. Este discurso apresenta a participação da sociedade civil como condição para a superação dos problemas sociais, mito este alimentado como forma de garantir o status quo por parte de agencias multilaterais e governos.

Este mito pode ser questionado na conjuntura atual caso as entidades da sociedade civil comprometidas com a radicalização da democracia tenham a capacidade de apresentar as atuais políticas públicas como responsáveis pelos processos de exclusão e mobilizar atores coletivos da sociedade, convertendo estes novos movimentos de protesto em movimentos sociais em favor de um processo desestabilizador da democracia formal, em um processo de invenção democrática. 


\section{Sobre o conceito de inclusão social}

O conceito de inclusão social, nas palavras do presidente do Banco Mundial, "é trazer as pessoas para uma sociedade da qual elas nunca fizeram parte até agora”. Segundo ele, "a nossa meta deve ser reduzir estas disparidades através das fronteiras e dentro desses países, integrar mais e mais as pessoas à economia, promover acesso eqüitativo aos benefícios do desenvolvimento, independentemente da nacionalidade, raça ou gênero. Este é o desafio da inclusão social - é o principal desafio do desenvolvimento em nossa era". ${ }^{27}$

O conceito de inclusão social nasce com seu par antitético o de exclusão social. Ambos tratam de múltiplos fenômenos relacionados com a questão da pobreza. Ambos não possuem historicidade, assim como os conceitos qualidade de vida ou desenvolvimento sustentável. O conceito de exclusão social pretende ser mais abrangente que o conceito de pobreza, ainda que o inclua. Mas para que servem?

"Tanto exclusão social como inclusão social não são conceitos analíticos. Estes são conceitos políticos, que foram introduzidos por motivos políticos. $\mathrm{O}$ conceito original do qual derivam estes outros é o da pobreza, que aparentemente foi considerado muito carregado por políticos que desejavam invisibilizar este fenômeno de produção da pobreza. Como os conceitos de exclusão social e inclusão social são abrangentes e envolvem vários tipos de fenômenos, sua utilização acaba por deslocar do centro do debate a questão da pobreza." 28

A utilização deste conceito de inclusão social - pelo seu caráter mais abrangente - permite, por exemplo, a apresentação de resultados positivos da ação dos governos e das agencias multilaterais, quando identifica a redução nas taxas de mortalidade infantil ou o aumento da esperança de vida das pessoas como indicadores do progresso. É verdade que estes indicadores têm melhorado em quase toda parte, até pelos avanços da ciência médica e de medicamentos que não existiam no passado. O conceito de inclusão social, no entanto, não fala de muitas coisas: do aumento da desigualdade, oculta o fato de que enfrentar a questão da pobreza requer que uma parcela da sociedade deixe de se apropriar do produto social como o faz hoje, não identifica a pobreza como uma construção histórica, o produto de políticas públicas, enfim, este conceito opera como o conceito de desenvolvimento: é

\footnotetext{
${ }^{27}$ WOLFENSOHN, James; "O Desafio da Inclusão"; discurso à Assembléia de Governadores; Hong Kong: China; 23 de setembro de 1997. ${ }^{28}$ OYEN, Else; "The contraditory concepts of social exclusion and social inclusion"; in Social Exclusion and anti-poverty policy: a debate; op.cit.
} 
um ponto de chegada, um mito, um telos que se anuncia na contramão dos processos sociais concretos.

O mito da inclusão social sustenta sua legitimidade enquanto discurso ideológico pela implementação das políticas compensatórias. Se alimenta dos "cases" de sucesso que são amplamente debatidos nos circuitos de formação de opinião. Não importa quão pequeno seja o grupo de pessoas beneficiadas. Para isso concorrem as premiações de experiências inovadoras em políticas públicas, a promoção dos trabalhos sociais das ongs, muito da produção universitária. Estas experiências são articuladas por um discurso que as utiliza para comprovar a viabilidade de suas propostas.

O principal objetivo desta política, deste discurso, é ocultar a natureza do processo societário que gera a pobreza e aprofunda a desigualdade social e sujeitar os grupos subalternos a buscarem a solução dos seus problemas pela via individual.

Tanto a discussão da exclusão social como a da inclusão social se centram na dimensão dos indivíduos. Trata-se de buscar a inclusão de indivíduos. Dissociadas das políticas macro-econômicas, estas estratégias focalizam o indivíduo e propõem soluções individuais como caminho da superação da pobreza. Melhor educação, apoio pelo micro-crédito, incubadora de micro-empresas, etc. A dimensão do coletivo, da sociedade, das políticas públicas, dos distintos interesses dos grupos e classes sociais, o espaço público, a política, tudo isso é suprimido deste discurso.

O núcleo duro desta discussão, portanto, é a questão das políticas públicas que geram a pobreza. É frente a elas que se deve desenvolver o maior esforço analítico. Trata-se de buscar associar as políticas macro-econômicas aos seus efeitos sociais perversos. Os estudos do Banco Mundial, no entanto, tem partido de uma noção de pobreza que reduz-se à privação de renda e capacidade de consumo dos indivíduos e das famílias, ainda que indicadores como esperança de vida, mortalidade infantil, acesso à educação sejam também levados em conta. ${ }^{29}$

As estratégias para combater a pobreza, concebidas pelo Banco Mundial, não tocam nas variáveis macro-econômicas. Elas se fundam nos seguintes elementos: promoção do crescimento econômico; diagnósticos específicos por país que permitam uma melhor focalização das ações de combate à pobreza; uma melhor coordenação das ações do Banco com os governos; o monitoramento dos programas para assegurar a articulação e a

\footnotetext{
29 "Poverty reduction and the World Bank - progress and challenges in the 1990s"; The World Bank; Washington; 1996.
} 
abrangência das estratégias de combate à pobreza; a avaliação in loco do impacto dos programas implementados; o reforço da capacidade institucional dos governos comprometidos com o combate à pobreza; a promoção da participação popular. ${ }^{30}$

As análises da evolução da pobreza e do impacto das ações financiadas pelo Banco, principalmente nos países do Sul, desafiam não só a concepção teórica como a capacidade de intervenção do Banco Mundial no combate à pobreza e à exclusão social.

Os temas da pobreza e da desigualdade social, podem, evidentemente, ser posto em outros termos. Recentes estudos da Organização Internacional do Trabalho identificam que a pobreza e a desigualdade social são produtos de políticas públicas. A partir desta conclusão, Vilmar Faria coloca, por exemplo, a seguinte questão: "se existem mecanismos que estão permanentemente produzindo a exclusão em um certo arranjo societário, quais são as implicações em termo de políticas? Seria modificar estes mecanismos básicos societários que constantemente produzem e reproduzem a exclusão? Ou estes mecanismos devem permanecer para sempre e o que se tem que desenvolver são políticas para compensar continuamente seus efeitos indesejáveis?". 31

Ao que parece, com essa pergunta, estão colocadas as questões centrais. O sentido a ser atribuído ao conceito de inclusão social será dado pelo próprio modelo de organização social que se quer construir. Tem a ver com a disputa em torno do projeto de futuro de cada sociedade determinada.

Reconhecendo a hegemonia do modelo de organização societária promotor da pobreza e da desigualdade social, Boaventura nos lembra que "Só há políticas sociais, porque a política dominante é anti-social. Se a política que nós temos fosse, ela própria, uma política social, no seu conjunto, nós não precisaríamos de políticas sociais, no sentido restrito em que delas falamos...Este modelo de políticas sociais do Banco Mundial e do FMI...se transforma numa condicionalidade: os diferentes países do mundo, quer estejam hoje no continente americano, asiático, africano ou no Leste Europeu, têm que seguir este modelo se quiserem ter acesso a crédito internacional: o Estado deve apenas ter políticas compensatórias, políticas que visam eliminar as formas extremas de pobreza e exclusão social originadas pelo mau funcionamento do mercado". ${ }^{32}$

\footnotetext{
30 "Poverty reduction and the World Bank - progress and challenges in the 1990s"; The World Bank; Washington; 1996 ; p. xiii.

${ }^{31}$ FARIA, Vilmar E.; "The social exclusion approach: some policy implications and priorities"; in "Social Exclusion and anti-poverty policy: a debate"; International Institute for Labour Studies; UNDP; Genebra; 1997; pag. 108.

${ }^{32}$ SANTOS, Boaventura de Sousa; "Em defesa das políticas sociais"; in "Políticas Sociais Para Um Novo Mundo Necessário e Possível"; 1 Seminário Balanço e Perspectivas das Políticas Sociais no Cenário Mundial Atual; II Fórum Social Mundial; Porto Alegre; 2002.
} 
Neste cenário mundial o grande esforço ideológico que se utiliza dos conceitos de inclusão/exclusão social é o esforço para naturalizar a pobreza, torná-la como que parte da natureza, algo inexorável, determinada, uma fatalidade como são as intempéries e os cataclismos. Contra elas o homem pode somente se empenhar para minimizar seu impacto.

Nesta matriz discursiva "o enigma da pobreza está inteiramente implicado no modo como direitos são negados na trama das relações sociais. Não é por acaso, portanto, que tal como figurada no horizonte da sociedade brasileira, a pobreza apareça despojada da dimensão ética e o debate sobre ela seja dissociado da questão da igualdade e da justiça. Pois essa é uma figuração que corresponde a uma sociedade em que direitos não fazem parte das regras que organizam a vida social. É uma figuração que corresponde ao modo como as relações sociais se estruturam sem outra medida além do poder dos interesses privados, de tal modo que o problema do justo e do injusto não se coloca e nem tem como se colocar, pois a vontade privada - e a defesa de privilégios - é tomada como a medida de todas as coisas". 33

Novamente aqui, de uma perspectiva de defesa e ampliação dos direitos de cidadania, a questão da pobreza e da desigualdade social demanda novas abordagens. Se a pobreza é entendida como a privação de direitos, o que se requer é a politização do social e a socialização da política. Se o resultado da produção da pobreza é a existência de indivíduos privados de seus direitos, a superação da pobreza requer mudanças profundas nas políticas públicas, requer, portanto, a ação de atores coletivos que, atuando no espaço público, possam incidir sobre os mecanismos de regulação do Estado e orientar sua ação em defesa do interesse público, da justiça social e da busca da equidade.

33 TELLES, Vera; "Pobreza e cidadania: figurações da questão social no Brasil moderno"; in TELLES, Vera; "Direitos sociais - afinal do que se trata?"; Ed. UFMG; Belo Horizonte; 1999; pág. 88. 